\title{
The Relationship between Computer Anxiety and Computer Self-Efficacy
}

\author{
Ali Simsek \\ Anadolu University, Turkey
}

\begin{abstract}
This study examined the relationship between computer anxiety and computer selfefficacy of students and teachers in elementary and secondary schools. The sample included a total of 845 subjects from two private school systems in Turkey. The Oetting's Computer Anxiety Scale was used to measure computer anxiety whereas the Murphy's Computer Self-Efficacy Scale was used to measure computer self-efficacy of subjects. The results demonstrated that elementary students were less-anxious than secondary students; males had lower anxiety scores than females; and the difference between anxiety scores of students and teachers was not significant. However, students had higher self-efficacy scores than their teachers; elementary students were more self-efficient than secondary students; and males had higher computer self-efficacy scores than females. The correlation between the variables of computer anxiety and computer self-efficacy was moderate, negative, and significant.
\end{abstract}

Keywords: Computer anxiety; Computer self-efficacy; Attitudes toward computers; Beliefs about computers; Elementary education; Secondary education

\section{Introduction}

Computers have made a dramatic impact on the contemporary society. Almost all aspects of our lives are affected by computers to a significant degree. It is even difficult to imagine a job or a task that we can complete without using computers. Of course, the field of education is no exception. Computers are used increasingly in teaching and learning processes within all subject areas at all levels of schooling.

Although some students are enthusiastic about computers, others may be apprehensive or reluctant (Arani, 2001; Doyle, Stamouli, \& Huggard, 2005). However, whether they feel comfortable or anxious regarding the role and use of computers in their lives, all students must be familiar with and even competent in using computers because this technology dominates all avenues of our societal as well as personal life. However, getting such a competence may not be easy for many reasons.

It is predicted that the more people use computers in their daily lives, the higher number of people will face difficulties with computers (Beckers \& Schmidt, 2001). Among other factors, computer anxiety may be a serious barrier against learning how to use computers effectively. On the other hand, although it has been studied for a long period of time, there is no clear-cut concensus regarding the definition and full scope of computer anxiety. 
Maurer (1994) defined computer anxiety as the fear and apprehension felt by an individual when considering the utilization of computer technology or when actually using it. Chua, Chen, and Wong (1999) also defined computer anxiety as a fear of computers when using one or fearing the possibility of using it when needed. According to these definitions, computer anxiety is characterized as an affective (to some extent emotional) response. It is different from negative attitudes toward computers that entail personal beliefs and feelings about computers rather than one's emotional reaction towards using computers (Sam, Othman, \& Nordin, 2005).

Computer anxiety has been conceptualized as a multi-dimensional construct. According to Torkzadeh and Angulo (1992), there are three major dimensions of computer anxiety as psychological, operational, and sociological. To be more concrete, psycghological dimension includes attitudes toward computers, self-efficacy, personality types, avoidance, and selfperceptions. Operational dimension usually results from computer courses, teachers, nature of computers, the extent of experiences with the computer, and owning a personal computer. Sociological dimension is related to factors of age, gender, nationality, socio-economic status, and the field of study.

Beckers and Schmidt (2001) suggest a six-factor computer anxiety model. The dimensions of this model are: (a) computer literacy of basic computer skills, (b) self-efficacy on learning how to use computers, (c) physical awareness while using computers such as breadthing or sweathing, (d) attitudes toward computers, (e) positive belief regarding the benefits of computers to society, and (f) negative beliefs on effects of computers.

Most of the research findings are mixed regarding the role of these factors on computer anxiety. However, research tends to support that more experiences with computers reduce the level of anxiety. This is particularly true when students start using computers at early ages, own a personal computer at home, use computers more frequently in daily life, and their academic major is a technical one (Chou, 2003; Gordon, Killey, Shevlin, Mcllroy, \& Tierney, 2003; Weil \& Rosen, 1995).

Researchers have proposed that lower computer anxiety and higher computer self-efficacy may be important factors in learning computer skills and employing them efficiently. On the other hand, some students may feel confused or even lost when they encounter computers as a result of negative perceptions of their own personal capabilities. This phenomenon, which is two-faceted with both negative and positive ends, is directly related to the concept of selfefficacy.

Kinzie, Delcourt, and Powers (1994) defined self-efficacy as an individual's confidence in his/her ability to perform a task for producing specific outcome, which may impact personal engagement, effort, and persistence. Within this context, computer self-efficacy is a specific type of self-efficacy referring to a belief of one's capability to use the computer (Compeau \& Higgins, 1995).

The amount of mental efforts that students make for acquiring computer skills or performing computer-related tasks may interact with their perceived self-efficacy in the computing field (Karsten \& Roth, 1998). If they think that they know enough or they can learn how to use computers easily, their anxiety may be low; alternatively, when they know little or think that it is difficult to learn/use computers, they may be more anxious (Konerding, 2007; Sam, Othman, Nordin, 2005). 
Webster and Martocchio (1992) demonstrated that computer self-efficacy has been positively related to performance during computer training. Zhang and Espinoza (1998), on the other hand, found that the less confident a student feels about computer skills, the more he/she desires to learn about computer technology. Harrington, McElroy, and Morrow (1990) supported that a high level of computer anxiety has been negatively related to learning computer skills. Torkzadeh and Angula (1992) suggested that students with higher level of computer anxiety exhibited more resistance to the use of computers.

There are also studies reporting that males on average have better computer self-efficacy and greater computer anxiety than females (Mcllroy, Bunting, Tierney, \& Gordon, 2001; Torkzadeh \& Koufteros, 1994). Several studies have even investigated female students' choice of courses and careers, and self-efficacy turned out to be a crucial predictor: Females had significantly lower self-efficacy than males in math related areas including computer science (Hackett, 1985). However, controlling for computer experience, males and females had similar interest toward computers (Badagliacco, 1990).

Recently it has been suggested that the contemporary male and female students alike are more pragmatic so that there may not be differences between genders and generalizations in terms of computers. Shaw and Giacquinta (2000) reported that two commonly held beliefs, that older students show more resistence than younger students toward computing for academic purposes and that males are more interested and skilled in the use of computers than females, are no longer accurate.

Taken together, these results suggest that computer anxiety and computer self-efficacy can have an important effect on computer use and ability to learn how to use computers. Then, the question becomes: Is there a direct relationship between computer anxiety and computer self-efficacy? If so, are demographic variables such as gender, age, and level of schooling affect this relationship?

The purpose of this study was to examine the relationship between computer anxiety and computer self-efficacy of students and teachers in elementary and secondary schools in the Turkish context. Toward this purpose, the following research questions were investigated: (a) To what degree students and teachers in elementary and secondary schools are anxious and self-efficient regarding the use of computers?; (b) Are there any significant differences in computer anxiety and computer self-efficacy of subjects in terms of their status, school level, and gender?; and (c) What is the correlation between computer anxiety and computer selfefficacy of students and teachers?

\section{Sample}

\section{Methods}

The sample of the study included a total of 845 subjects from two private school systems in Turkey. One of the school systems was located in Eskisehir, a Central-Anatolian province $(n=308) ;$ while the other was located in Zonguldak, a Black Sea province $(n=537)$. Of the total sample, $722(85 \%)$ were students and $123(15 \%)$ were teachers. The student sub-sample consisted of $399(47 \%)$ secondary and $323(38 \%)$ elementary students, while the teacher subsample comprised of $53(7 \%)$ secondary and $70(8 \%)$ elementary school teachers. With regard to gender, 391 subjects (46\%) were male, 454 subjects (54\%) were female. Within the student 
sub-sample, proportions of males and females were relatively close (49\% male and $51 \%$ female); however, females were disproportionately higher than males among teachers $(69 \%$ female and $31 \%$ male). Table 1 illustrates the details of the sample.

Table 1. Distribution of Subjects According to Status, School Levels, and Gender

\begin{tabular}{|c|c|c|c|c|c|c|c|c|c|c|}
\hline \multirow[t]{2}{*}{ Status } & \multicolumn{4}{|c|}{ Male } & \multicolumn{3}{|c|}{ Female } & \multicolumn{3}{|c|}{$\underline{\text { Total }}$} \\
\hline & & $\underline{\text { Student }}$ & $\underline{\text { Teacher }}$ & $\underline{\text { Total }}$ & $\underline{\text { Student }}$ & Teacher & $\underline{\text { Total }}$ & $\underline{\text { Student }}$ & $\underline{\text { Teacher }}$ & Total \\
\hline \multirow[t]{2}{*}{ Elementary } & $\mathrm{n}:$ & 165 & 19 & 184 & 158 & 51 & 209 & 323 & 70 & 393 \\
\hline & $\%:$ & 20 & 02 & 22 & 19 & 06 & 25 & 38 & 08 & 46 \\
\hline \multirow[t]{2}{*}{ Secondary } & $\mathrm{n}:$ & 188 & 19 & 207 & 211 & 34 & 245 & 399 & 53 & 452 \\
\hline & $\%:$ & 22 & 02 & 24 & 25 & 04 & 29 & 47 & 07 & 54 \\
\hline \multirow[t]{2}{*}{ General } & $\mathrm{n}:$ & 353 & 38 & 391 & 369 & 85 & 454 & 722 & 123 & 845 \\
\hline & $\%:$ & 42 & 04 & 46 & 44 & 10 & 54 & 85 & 15 & 100 \\
\hline
\end{tabular}

A significant majority of students in both school systems came from a middle-class family background and almost all of them had personal computers at home. They had either taken computer literacy courses or learned the use of computers on their own. On the teachers' side, two-thirds of them were seniors with a teaching career of more than fifteen years. These teachers did not take any pre-service computer course during their college years; however, the junior teachers, that made one-third of the teacher sub-sample, took formal computer courses when they were studying at the university.

\section{Instruments}

In order to measure computer anxiety, the Oetting's (1983) Computer Anxiety Scale (COMPAS) was used in the study. After some adaptations, the scale was pilot-tested in two different schools, one elementary and one secondary school. This Likert-type scale included a total of 40 items. It had six sub-categories: The category of the overall computer anxiety included half of the items ( 20 items), and the other 20 items were equally ( 4 items for each) distributed into the remaining sub-categories of general attitude, data entry, word-processing, business operations, and computer science. The overall Cronbach's Alpha reliability coefficient for the entire scale was calculated to be 0.92 . The reliability coefficient for student responses was 0.91 whereas the reliability coefficient for teacher responses was 0.94 .

On this scale, the total scores ranged 40-79 are considered "relaxed", 80-104 are considered "generally relaxed and comfortable", 105-129 are considered "some mild anxiety present", 130-149 are considered "anxious and tense", and 150-200 are considered "very anxious". Scoring of the sub-scales is as follows: 4-8 very relaxed and confident, 9-10 generally relaxed and comfortable, 11-12 some mild anxiety present, 13-14 anxious and tense, 15-20 very anxious.

Computer self-efficacy was measured with the Murphy's (1989) Self-Efficacy Scale. The general validation procedures of this scale were similar to the validation process for COMPAS. The final version of this Likert-type scale included a total of 32 items. It had three sub-categories: Beginning skills ( 16 items), advanced skills ( 13 items), and mainframe skills ( 3 items). The 
overall Cronbach's Alpha reliability coefficient for the entire scale was calculated to be 0.96 . The reliability coefficient was 0.96 for student responses and 0.98 for teacher responses.

\section{Procedures}

The schools were contacted for their suitability for the study. School administrators were informed about important details of the study in face-to-face meetings. Following the consent procedures, the purpose of the study was explained to teachers by the school administrators. The teachers completed the scales and returned them to the executive secretary of their schools. During the following several days, the teachers administered the scales to students in their classes and returned them to the school administrations.

All the subjects were asked to write down their names or personal codes on the scales because their scores would be reported to them individually, and also used by the school for the purpose of providing their students with instructional support. However, a small number of students did not write their names or codes so that their scores were excluded from the analysis because the calculation of correlation required matching of the anxiety and selfefficacy scores of each individual.

\section{Findings}

In order to analyze data toward the research questions, both descriptive and inferential statistical techniques were used in the study. The findings produced with these techniques were depicted in relevant tables and their interpretations were presented in corresponding paragraphs. The findings were organized basically under the titles of the dependent variables of the study.

\section{Computer Anxiety}

A descriptive summary of the findings related to computer anxiety scores was presented in Table 2. The overall mean of computer anxiety scores was moderate $(M=87.89)$. This means that the subjects in this study were "generally relaxed and comfortable." It is interesting that the mean scores for all the independent variables are within the limits of moderate anxiety $(M=88.12$ for students and $M=86.59$ for teachers; $M=84.99$ for elementary school subjects and $M=90.41$ for secondary school subjects; $M=92.24$ for females and $M=82.84$ for males).

The difference between anxiety scores of students and teachers was not statistically significant $[\underline{F}(1,843)=0.496 ; \underline{p}=.481]$. When the school level was considered, the difference was significant $[\underline{F}(1,843)=12.633 ; \underline{p}<.0001]$. Within the student sub-sample, elementary students were lessanxious than secondary students $[\underline{F}(1,720)=12.891 ; \underline{p}<.0001]$, but there was no significant difference among elementary and secondary school teachers $[\underline{E}(1,121)=0.208 ; \underline{p}=.649]$. The difference between anxiety scores of male and female subjects was significant $[\mathrm{F}(1,843)=39.208 ; \mathrm{p}<.0001]$, males having lower anxiety scores than females.

A series of stepwise multiple regression tests were conducted to find out which sub-category explained computer anxiety best. The results demonstrated that "overall anxiety" was the best individual predictor of the total computer anxiety score $\left(\mathrm{R}^{2}=.913\right)$, whereas "general attitude" 
was the weakest individual predictor $\left(\mathrm{R}^{2}=.456\right)$. However, all the sub-categories contributed significantly $(\underline{p}<.0001)$ to the total anxiety score. The combination of the best two predictors (overall anxiety and data entry) accounted for $95 \%$, while the combination of the best five predictors (overall anxiety, data entry, business operations, word processing, and computer science) accounted for $99 \%$ of the total score.

Table 2. Means and Standard Deviations for Computer Anxiety Scores

\begin{tabular}{|c|c|c|c|c|c|c|c|c|c|c|}
\hline \multirow[t]{2}{*}{ Status } & & \multicolumn{3}{|c|}{ Male } & \multicolumn{3}{|c|}{ Female } & \multicolumn{3}{|c|}{ Total } \\
\hline & & $\underline{\text { Student }}$ & Teacher & $\underline{\text { General }}$ & $\underline{\text { Student }}$ & $\underline{\text { Teacher }}$ & General & $\underline{\text { Student }}$ & $\underline{\text { Teacher }}$ & $\underline{\text { General }}$ \\
\hline \multirow[t]{3}{*}{ Elementary } & M: & 79.90 & 78.21 & 79.72 & 89.95 & 88.65 & 89.63 & 84.81 & 85.81 & 84.99 \\
\hline & SD: & 22.24 & 16.46 & 21.69 & 21.21 & 21.74 & 21.29 & 22.28 & 20.86 & 22.01 \\
\hline & $\mathrm{N}:$ & 165 & 19 & 184 & 158 & 51 & 209 & 323 & 70 & 393 \\
\hline \multirow[t]{3}{*}{ Secondary } & M: & 86.15 & 80.21 & 85.61 & 94.91 & 91.74 & 94.47 & 90.78 & 87.60 & 90.41 \\
\hline & SD: & 23.71 & 20.31 & 23.44 & 19.80 & 22.70 & 20.20 & 22.14 & 22.38 & 22.17 \\
\hline & $\mathrm{N}:$ & 188 & 19 & 207 & 211 & 34 & 245 & 399 & 53 & 452 \\
\hline \multirow[t]{3}{*}{ General } & M: & 83.23 & 79.21 & 82.84 & 92.79 & 89.88 & 92.24 & 88.12 & 86.59 & 87.89 \\
\hline & SD: & 23.22 & 18.27 & 22.79 & 20.53 & 22.05 & 20.83 & 22.39 & 21.46 & 22.25 \\
\hline & $\mathrm{N}:$ & 353 & 38 & 391 & 369 & 85 & 454 & 722 & 123 & 845 \\
\hline
\end{tabular}

\section{Computer Self-Efficacy}

A summary of descriptive statistics about computer self-efficacy scores was presented in Table 3. The average computer self-efficacy score for the overall sample was relatively high $(M=128.93)$. Considering that the minimum possible score for the entire scale used in the study was 32 and the maximum possible score was 160, the general level of the subjects was above $80 \%$ level, which indicated "high confidence." When the findings were further analyzed according to sub-samples, it was found that male elementary students had the highest average score of computer self-efficacy $(M=138.90)$, while female secondary school teachers had the lowest average of self-efficacy scores ( $M=117.59)$.

The difference between students' and teachers' self-efficacy scores was statistically significant $[\mathrm{F}(1,843)=21.852 ; \mathrm{p}<.0001]$. The difference between the school levels was also significant $[\mathrm{F}(1,843)=15.867 ; \underline{\mathrm{p}}<.0001]$. Elementary students were more self-efficient than secondary students $[\mathrm{F}(1,720)=27.291 ; \mathrm{p}<.0001]$, but the difference between elementary and secondary school teachers was not significant $[\mathrm{F}(1,121)=0.011 ; \mathrm{p}=.917]$. The difference with regard to gender of the subjects was also significant $[\mathrm{F}(1,843)=53.382 ; \underline{\mathrm{p}}<.0001]$, males having higher computer self-efficacy scores than females.

Stepwise multiple regression analyses demonstrated that beginning level computer skills was the best individual predictor $\left(R^{2}=.898\right)$ for computer self-efficacy, advanced skills was the second $\left(R^{2}=.863\right)$, and mainframe skills was the weakest individual predictor $\left(R^{2}=.479\right)$. The combination of the best-two predicting group of computer skills (beginning and advanced skills) accounted for $99 \%$ of the total score, leaving very little or no chance for additional contribution of mainframe skills. 
Table 3. Means and Standard Deviations for Computer Self-Efficacy Scores

\begin{tabular}{|c|c|c|c|c|c|c|c|c|c|c|}
\hline \multirow[t]{2}{*}{ Status } & \multicolumn{4}{|c|}{ Male } & \multicolumn{3}{|c|}{ Female } & \multicolumn{3}{|c|}{ Total } \\
\hline & & $\underline{\text { Student }}$ & $\underline{\text { Teacher }}$ & $\underline{\text { General }}$ & $\underline{\text { Student }}$ & $\underline{\text { Teacher }}$ & $\underline{\text { General }}$ & $\underline{\text { Student }}$ & $\underline{\text { Teacher }}$ & General \\
\hline \multirow[t]{3}{*}{ Elementary } & M: & 138.90 & 122.79 & 137.24 & 129.30 & 122.33 & 127.11 & 134.21 & 121.00 & 131.86 \\
\hline & SD: & 14.46 & 27.60 & 19.93 & 16.92 & 24.50 & 19.37 & 16.41 & 25.20 & 18.94 \\
\hline & $\mathrm{N}:$ & 165 & 19 & 184 & 158 & 51 & 209 & 323 & 70 & 393 \\
\hline \multirow[t]{3}{*}{ Secondary } & M: & 131.81 & 128.47 & 131.50 & 122.80 & 117.59 & 122.07 & 127.04 & 121.49 & 126.39 \\
\hline & SD: & 19.03 & 21.34 & 19.22 & 19.43 & 28.45 & 20.92 & 19.74 & 26.44 & 20.68 \\
\hline & $\mathrm{N}:$ & 188 & 19 & 207 & 211 & 34 & 245 & 399 & 53 & 452 \\
\hline \multirow[t]{3}{*}{ General } & M: & 135.13 & 125.63 & 134.21 & 125.58 & 119.24 & 124.39 & 130.25 & 121.21 & 128.93 \\
\hline & SD: & 17.39 & 24.50 & 18.38 & 18.65 & 26.02 & 20.35 & 18.66 & 25.63 & 20.06 \\
\hline & $\mathrm{N}:$ & 353 & 38 & 391 & 369 & 85 & 454 & 722 & 123 & 845 \\
\hline
\end{tabular}

\section{Relationships among Variables}

The overall correlation coefficient between computer anxiety and computer self-efficacy was negative but significant $(r=-0.52 ; \mathrm{p}<.01)$. This mid-level correlation coefficient generally implies that when the level of computer self-efficacy increases, the level of computer anxiety decreases and vice versa.

As far as the relationship between computer anxiety and its sub-categories was concerned, all the sub-categories were significantly correlated with computer anxiety. The most correlating category was "overall anxiety" ( $r=.956 ; \underline{p}<.01)$, and the weakest correlation was found for "general attitude" ( $r=.675 ; \mathrm{p}<.01)$. Furthermore, all sub-categories were significantly $(\mathrm{p}<.01)$ correlated with each other, ranging from $r=.382$ (general attitude and computer science) to $r=.685$ (overall anxiety and computer science).

The correlations between computer self-efficacy and its subcategories were all significant. The best correlation was found for beginning skills ( $r=.948 ; \underline{p}<.01)$, the second for advanced skills $(r=.929 ; \mathrm{p}<.01)$, and the weakest for mainframe skills $(r=.692 ; \mathrm{p}<.01)$. Correlations among subcategories of computer self-efficacy were all significant $(\underline{p}<.01 ; r=.776$ for beginning and advanced skills, $r=.655$ for beginning and mainframe skills, and $r=.535$ for advanced and mainframe skills).

\section{Discussion}

The average computer-anxiety level of subjects in the present study was medium; that is, the subjects were "generally relaxed and comfortable" about computers. The situation did not differ for students and teachers. However, elementary students had lower computer-anxiety scores than secondary students; although the difference between anxiety levels of elementary school teachers and high school teachers was not significant. It may be thought that social backgrounds and teaching contexts are similar for teachers in these schools. They also share 
similar development opportunities and working conditions. However, backgrounds of students including age differences and personal experiences with the current technology might have created the differences among them.

Generally speaking, the burgeoning developments in the computer technology are difficult to follow, particularly for older generations. Elementary students have better chances in this area. Supporting data in the present study showed that elementary students use the computer more than secondary students and teachers. Because they are normally more exposed to new technologies, such an experience might have contributed to the fact that elementary students were less anxious than any other group in the study (Hasan, 2003). In fact, Koroboli, Togia, and Malliari (2010) reported that computer anxiety was correlated positively with PC ownership, access to computers at younger ages, and frequency of computer use.

Students had higher computer self-efficacy scores than teachers. Again, the average computer self-efficacy score for elementary students was higher than the average score for high school students. On the other hand, there was no such difference between average computer selfefficacy scores of secondary and elementary school teachers.

It is understandable that students feel more self-efficient about computers than their teachers. As supporting data in the study suggest, students use the current technology for a variety of purposes and explore alternative ways and usages, while most teachers use the computer for simple tasks such as office applications and Internet searches. This is somewhat similar to the findings of Sam, Othman, and Nordin (2005) suggesting that undergraduate students used the Internet extensively for educational purposes such as doing research, downloading electronic resources, and e-mail communications. Of course, this situation makes a big difference since more exposure means more familiarity and efficiency (Doyle, Stamouli, \& Huggard, 2005). It was also interesting to observe that teachers' workloads in the participating schools were relatively high and they did not have enough time to use and make important discoveries about computers. Therefore, they often report that their students are much better computer users than themselves.

Male subjects were less anxious and more self-efficient about computers than female subjects. This result was consistent across status and school level variables. In other words, female students and teachers reported high computer anxiety and low computer self-efficacy than their male counterparts both in the elementary and secondary school levels. Although Sam, Othman, and Nordin (2005) reported different findings, it appears that being male or female plays a much more significant role in computer anxiety and computer self-efficacy than whether the person is a student or a teacher (Miura, 1987). It is also true that whether someone studies/works at the elementary or secondary school does not make a lot of difference compared to the gender of the person.

Of course, this result should be interpreted within the cultural contexts rather than limiting the discussion into school settings. Starting from the early years, the field of technology is often considered a male area and boys are provided with more chances to get acquainted with "hard areas" including computer. On the other hand, girls are directed formally or informally to "soft fields" which are defined as non-technical. Then, the school becomes an institution that makes youngsters reinforce these stereotypes without questioning. It appears that this process works just the same in the Turkish context. 
The results of the present study show that there is a meaningful negative correlation between computer anxiety and computer self-efficacy. This comes as no surprise because as people know and feel better about accomplishing a task, they perceive more chances for success so that their anxiety gets lower (Brosnan, 1998; Johnson, 2005; Roslan \& Mun, 2005). Similarly, higher general Internet self-efficacy produces more preferences toward Internet learning environments where they can use with ease, explore real-life problems, display multiple sources of information, conduct open-ended inquiry learning activities, and elaborate the nature of knowledge (Liang \& Tsai, 2008). Considering that both very-low and very-high anxiety levels are detrimental for performance, moderate anxiety level appears to contribute more to achieving crucial and difficult goals such as computing. It is important to note that the subjects in the present study reported "moderate anxiety" and "high self-efficacy" about computers. Fortunately, this appears to be an ideal situation for accommodating their learning needs in the area of technology for all subjects.

The results of this study suggest a number of new studies for the future. First, similar studies should be conducted in various school settings representing different cultures, socio-economic status, geographical areas, and ethnic backgrounds. Second, further studies should look more closely at differences among grade levels to find out turning points/ages so that necessary measures can be taken on time. Third, effects of individual differences on computer anxiety and computer self-efficacy should be investigated; particular emphasis should be given to ability, learning style, prior knowledge, locus of control, personality type, and epistemological beliefs. Fourth, considering that the scales employed in the present study are relatively subjective (based on self-reporting), more objective (probably performance-based) measures of computer anxiety and computer self-efficacy should be developed and employed in future studies. Finally, new studies should be carried out to explore effective training strategies to overcome computer anxiety and increase computer self-efficacy.

\section{References}

Arani, O. K. (2001). Researching computer self-efficacy. International Education Journal, 2(4), 17-25.

Badagliacco, J. M. (1990). Gender and race differences in computing attitudes and experience. Social Science Computer Review, 8, 42-64.

Beckers, J. J. \& Schmidt, H. G. (2001). The structure of computer anxiety: A six-factor model. Computers in Human Behavior, 17(1), 35-49.

Brosnan, M. J. (1998). The impact of computer anxiety and self-efficacy upon performance. Journal of Computer Assisted Learning, 14(3), 223-234.

Chou, C. (2003). Incidences and correlates of Internet anxiety among high school teachers in Taiwan. Computers in Human Behavior, 19, 731-749

Chua, S. L., Chen, D., \& Wong, A. F. L. (1999). Computer anxiety and its correlates: A metaanalysis. Computers in Human Behavior, 15, 609-623.

Compeau, D. R. \& Higgins, C. A. (1995). Computer self-efficacy: Development for a measure and initial test. MIS Quarterly, 19, 189-211.

Doyle, E., Stamouli, I., \& Huggard, M. (2005, October). Computer anxiety, self-efficacy, and computer experience: An investigation throughout a computer science degree. Paper presented at the $35^{\text {th }}$ ASEE/IEEE Frontiers in Education Conference. Indianapolis, USA. 
Gordon, M., Killey, M., Shevlin, M., Mcllroy, D., \& Tierney, K. (2003). The factor structure of the Computer Anxiety Rating Scale and the Computer Thoughts Survey. Computers in Human Behavior, 19, 291-298

Hackett, G. (1985). The role of mathematics self-efficacy in the choice of math-related majors of college women and men: A path analysis. Journal of Counseling Psychology, 32, 4756.

Hasan, B. (2003). The influence of specific computer experiences on computer self-efficacy beliefs. Computers in Human Behavior, 19, 443-450.

Harrington, K. V., McElroy, J. C., Morrow, P. C. (1990). Computer anxiety and computer-based training: A laboratory experiment. Journal of Educational Computing Research, 6, 343358.

Johnson, R. D. (2005). An empirical investigation of sources of application specific computer self-efficacy and mediators of the efficacy-performance relationship. International Journal of Human-Computer Studies, 62(6), 737-758.

Karsten, R. \& Roth, R. M. (1998). Computer self-efficacy: A practical indicator of student computer competency in introductory IS courses. Informing Science, 1(3), 61-68.

Kinzie, M. B., Delcourt, M. A. B., Powers, S. M. (1994). Computer technologies: Attitudes and self-efficacy across undergraduate disciplines. Research in Higher Education, 35, 745768.

Konerding, U. (2007). The effects of two computer-related university courses on computer anxiety and computer self-efficacy. Retrieved on March 3, 2007 from: http://www.educat.hu-berlin.de/mv/forschung/zero.thm

Koroboli, S. \& Togia, A., \& Malliari, A. (2010). Computer anxiety and attitudes among undergraduate students in Greece. Computers in Human Behavior, 26(3), 399-405.

Liang, J. C. \& Tsai, C. C. (2008). Internet self-efficacy and preferences toward constructivist Internet-based learning environments: A study of pre-school teachers in Taiwan. Educational Technology \& Society, 11(1), 226-237.

Maurer, M. M. (1994). Computer anxiety correlates and what they tell us: A literature review. Computers in Human Behavior, 10(3), 369-376.

Mcllroy, D., Bunting, B., Tierney, K., \& Gordon, M. (2001). The relation of gender and background experience to self-reported computing anxiety and cognitions. Computers in Human Behavior, 17(1), 21-33.

Miura, I. T. (1987). The relationship of computer self-efficacy expectations to computer interest and course enrollment in college. Sex Roles, 16(5-6), 303-311.

Roslan, S. \& Mun, T. C. (2005). Relationships between sources and dimensions of computer anxiety. Malaysian Online Journal of Instructional Technology, 2(2), 41-49.

Sam, H. K., Othman, A. E. A., Nordin, Z. S. (2005). Computer self-efficacy, computer anxiety, and attitudes toward the Internet: A study among undergraduates in Unimas. Educational Technology \& Society, 8(4), 205-219.

Shaw, F. S. \& Giacquinta, J. B. (2000). A survey of graduate students as end users of computer technology: New roles for the faculty. Information Technology, Learning, and Performance Journal, 18(1), 21-39. 
Tourkzadeh, G. \& Angula, I. E. (1992). The concept and correlates of computer anxiety. Behavior and Information Technology, 11, 99-108.

Tourkzadeh, G. \& Koufterous, X. (1994). Factorial validity of a computer self-efficacy scale and the impact of computer training. Educational and Psychological Measurement, 54(3), 813-921.

Webster, J. \& Martocchio, J. J. (1992). Microcomputer playfulness: Development of a measure with workplace implications. MIS Quarterly, 16(2), 201-226.

Weil, M. M. \& Rosen, L. D. (1995). The psychological impact of technology from a global perspective: A study of technological sophistication and technophobia in university students from twenty three countries. Computers in Human Behavior, 11(1), 95-133.

Zhang, Y. \& Espinoza, S. (1998). Relationships among computer self-efficacy, attitudes toward computers, and desirability of learning computing skills. Journal of Research on Technology in education, 30(4), 420-436.

Correspondence: Ali Simsek, Professor, Institute of Communication Sciences, Anadolu University, Yunus Emre Campus, Eskisehir 26470, Turkey 